\title{
Dietary carnosic acid, selenized yeast, selenate and fish oil affected the concentration of fatty acids, tocopherols, cholesterol and aldehydes in the brains of lambs
}

\author{
Agnieszka J. Rozbicka-Wieczorek, Katarzyna A. Krajewska-Bienias, and Marian Czauderna \\ The Kielanowski Institute of Animal Physiology and Nutrition, \\ Polish Academy of Sciences, 05-110 Jabłonna, Poland \\ Correspondence to: Marian Czauderna (m.czauderna@ifzz.pl)
}

Received: 9 November 2015 - Revised: 2 May 2016 - Accepted: 13 May 2016 - Published: 25 May 2016

\begin{abstract}
The function of the brain is to exert centralized control over the other internal organs and tissues of the body. Thus, the objective of our studies was to evaluate changes in the concentration of fatty acids (FAs), cholesterol (CHOL), cholest-4-en-3-one (CHOL-4-3), tocopherols, malondialdehyde (MDA) and fatty aldehydes in the brains of lambs fed supplemented diets. Thirty male Corriedale lambs with a body weight of $30.5 \pm 2.6 \mathrm{~kg}$ were allotted to five groups of six lambs and housed individually. After the preliminary period, for 35 days the animals were fed a diet containing 3\% rapeseed oil (RO) (the RO diet), a diet enriched with $2 \%$ RO and $1 \%$ fish oil (FO) (the FO diet) or the diets with combined addition of $2 \%$ RO, $1 \%$ FO, $0.1 \%$ carnosic acid (CA) (the CA diet) and $0.35 \mathrm{ppm} \mathrm{Se}$ as the selenized yeast (SeY) (the CASeY diet) or selenate (SeVI) (the CASeVI diet). The CASeVI diet most efficiently increased the accumulation of FAs (including unsaturated FAs), CHOL4-3 and fatty aldehydes in the lamb brain. This diet most effectively decreased the concentration of CHOL and MDA in the brain. The CASeY diet showed a different impact on the level of FAs, CHOL, CHOL-4-3, tocopherols, MDA and fatty aldehydes in the brain as compared with the CASeVI diet. The CA diet reduced the concentration of CHOL-4-3, the sums of fatty aldehydes, FAs, atherogenic- and thrombogenic-saturated FAs in the brain compared with the CASeVI diet; the CA diet most effectively increased the value of polyunsaturated FA (PUFA) peroxidation index in the brain. The RO diet most efficiently increased the concentration of CHOL and values of the ratios of saturated FAs to PUFAs and long-chain $n$-6PUFAs to long-chain $n$-3PUFAs in the brain.

The current studies provide new useful information for nutritionists carrying out further investigations aimed at improving farm-animal health, growth performance, reproductive system and the nutritional quality of feed for ruminants.
\end{abstract}

\section{Introduction}

Reactive oxygen agents are known to elicit oxidative damage of cholesterol (CHOL), its metabolites (like cholest-4en-3-one) and polyunsaturated fatty acids (PUFAs), especially long-chain PUFAs (LPUFAs) (Xiao et al., 2009; Orth and Bellosta, 2012; Sultana et al., 2013). Cholest-4-en-3one (CHOL-4-3) and other CHOL metabolites inhibit body weight gain and body fat content (Suzuki et al., 1998). The brain is sensitive to oxidative damage since it contains high contents of CHOL, its metabolites and oxidizable LPUFAs (like C22:6n-3 (DHA) and C20:4n-6 (ArA)) (Patterson et al., 2012; Rosa et al., 2013) and is poorly endowed with protective antioxidant enzymes (Stadelmann-Ingrand et al., 2004). Oxidative damage of PUFAs leads to the formation of aldehydic end-products, including malondialdehyde (MDA), 4hydroxy-2,3-nonenal (4-HNE) or 4-hydroxy-2,3-alkenals (4HAKs) of different chain length; 4-HNE and 4-HAKs are active molecules in physiological or pathological conditions (Sultana et al., 2013). Aldehydes may be produced during decomposition of hydroperoxides of fatty acids (FAs) (Albert et al., 2013). Aldehydes can affect several cell functions, 
including signal transduction, gene expression, cell proliferation and more generally the response of the target cells (Stadelmann-Ingrand et al., 2004). Fatty aldehydes are naturally occurring species in tissues (Dannenberger et al., 2006; Chen at al., 2011); for example, during the synthesis of sphingosine by the brain, palmitoyl CoA is reduced by NADPH to palmitic aldehyde, which is then reincorporated into dihydrosphingosine (Sultana et al., 2013).

The susceptibility of tissues to a radical attack is a function of the balance between the magnitude of the oxidative stress and its own antioxidant potential. Studies have shown that adequate levels of Se, carnosic acid (CA) or tocopherols in diets protect against the oxidative degradation of CHOL, CHOL metabolites (like CHOL-4-3), unsaturated FAs (UFAs) and accumulation of carbonyl moieties on proteins produced by oxidative stress (Han et al., 2009; Morán et al., 2012). CA can modify microbiota, resulting in changes of the ruminal bacterial metabolism (Jordan et al., 2013). Similarly, Se compounds are used as nutritional sources of Se. The chemical form of dietary Se affects a synthesis yield of Se complexes and Se proteins in ruminal microorganisms (Mainville et al., 2009). Se derived from dietary selenized yeast $(\mathrm{SeY})$ is more efficiently accumulated in the animal's body than inorganic forms of Se (e.g. selenate) (Navarro-Alarcon and Cabrera-Vique, 2008). The principal physiological roles of Se proteins are to maintain the appropriate metabolism of ArA and low levels of free radicals within cells, thus decreasing oxidative stress and peroxidative damage of lipids and CHOL in tissues (Tapiero et al., 2003; Schweizer et al., 2005; Yu et al., 2008).

Considering the above, we hypothesized that selenate (SeVI) or especially $\mathrm{SeY}$ added to the diet with $\mathrm{CA}$ and fish oil (FO) would reduce levels of fatty aldehydes, MDA, CHOL and CHOL-4-3 (the neuro-protector; Xiao et al., 2009) in the ruminal brain. Importantly, the brain comprises the body's central nervous system (Martin et al., 2004; Ogata et al., 2011).

Thus, the first aim of our study was to explore effects of FO added to the diet with rapeseed oil (RO) on contents of FAs, CHOL, CHOL-4-3, tocopherols and MDA (the marker of lipid peroxidation) and fatty aldehydes in the lamb brain. We expect that $1 \%$ FO (rich in LPUFA) added to the diet with $2 \% \mathrm{RO}$ will be stimulated the oxidative stress in the brain compared with the diet with $3 \%$ RO. RO (rich in C18:2n-6 (LA)) was added to the diet because RO stimulated the synthesis of health-promoting conjugated LA isomers in ruminants (Lee and Jenkins, 2011); moreover, LA is the precursor of ArA, which plays important physiological functions in the ruminant brain (Patterson et al., 2012; Rosa et al., 2013).

The second aim of our study was to investigate effects of different chemical forms of $\mathrm{Se}$ (as $\mathrm{SeY}$ or $\mathrm{SeVI}$ ) added to the diet with CA, FO and RO on levels of FAs, tocopherols, MDA, CHOL, CHOL-4-3 and fatty aldehydes in the brain. We expect that $\mathrm{SeY}$ and SeVI added to the diet will be re-
Table 1. Chemical composition of the concentrate-hay diet with vitamins and mineral mixture (the basal diet) and odourless fish oil $(\mathrm{FO})^{\mathrm{a}}$ fed to lambs.

\begin{tabular}{|c|c|c|c|c|}
\hline \multirow[b]{2}{*}{ Specification $^{\mathrm{b}}$} & \multirow[b]{2}{*}{$\begin{array}{c}\text { Meadow } \\
\text { hay }^{\mathrm{d}}\end{array}$} & \multicolumn{3}{|c|}{ Concentrate $^{\mathrm{c}}$} \\
\hline & & $\begin{array}{c}\text { Barley } \\
\text { meal }\end{array}$ & $\begin{array}{c}\text { Soybean } \\
\text { meal }\end{array}$ & $\begin{array}{l}\text { Wheat } \\
\text { starch }\end{array}$ \\
\hline Dry matter $(\%)$ & 88.4 & 87.6 & 89.7 & 87.3 \\
\hline Crude protein $(\%)$ & 9.50 & 9.94 & 41.8 & 0.90 \\
\hline Crude fibre $(\%)$ & 27.3 & 2.87 & 4.34 & - \\
\hline Crude fat $(\%)$ & 3.40 & 2.50 & 2.25 & 0.09 \\
\hline Ash $(\%)$ & 4.85 & 1.84 & 6.16 & 0.12 \\
\hline Neutral detergent fibre $(\%)$ & 59.2 & 18.0 & 18.8 & - \\
\hline Acid detergent fibre $(\%)$ & 32.1 & 4.61 & 6.44 & - \\
\hline Acid detergent lignin (\%) & 4.47 & 1.14 & 1.49 & - \\
\hline \multicolumn{5}{|c|}{ 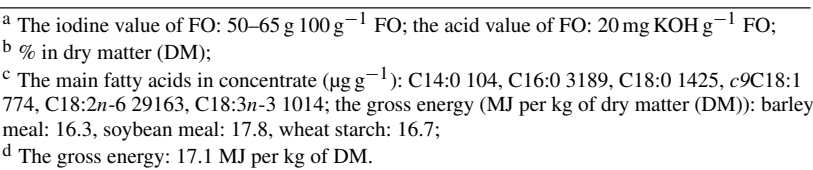 } \\
\hline
\end{tabular}

duced oxidative stress in the brain compared with the diet with $\mathrm{CA}, \mathrm{FO}$ and RO.

\section{Material and methods}

\subsection{Animals and experimental design}

Thirty male Corriedale lambs were carefully selected from a large herd of lambs $(\sim 110$ male lambs). Thus, selected lambs have similar body weight $(23.3 \pm 2.1 \mathrm{~kg})$ and age (8290 days). During a 3-week preliminary period the lambs were given free access to the basal diet (the standard concentratehay diet with vitamins and mineral premix) (Table 1); water was offered ad libitum. The basal diet (BD) consists of the following components: meadow hay $(\sim 36 \%)$, a mixture of soybean meal $(\sim 36 \%)$, barley meal $(\sim 16.5 \%)$, wheat starch $(\sim 9 \%)$ and mineral-vitamin mixture $\left(20 \mathrm{~g} \mathrm{~kg}^{-1} \mathrm{BD}\right)$. The basal diet contains crude protein $120 \mathrm{~g}$, crude fibre $12 \mathrm{~g}$, and $11 \mathrm{MJ}$ metabolizable energy in $1 \mathrm{~kg}$ dry mater. The basal diet was enriched in $3 \%$ rapeseed oil (RO) (the RO diet) or $2 \%$ RO and $1 \%$ odourless FO (the FO diet) (Table 2).

After a 3-week preliminary period, 30 lambs with an average body weight (BW) of $30.5 \pm 2.6 \mathrm{~kg}$ at the beginning of the experiment were individually penned and divided into 5 groups of 6 lambs (Table 2). The animals were distributed into five groups according to the initial weights of lambs, so that the average initial body weights of lambs between the groups were similar. This study was conducted under the authority of the Third Local Commission of Animal Experiment Ethics at the University of Life Sciences, 02-786 Warsaw, Poland.

In the first experiment (Table 2), for the next 35 days following the 3-week preliminary period the lambs were fed the $\mathrm{RO}$ diet (the non-supplemented diet; group RO) or the FO diet (group FO). 
Table 2. The experimental scheme and the composition of the experimental diets, the body weight (BW) of lambs and brain masses ${ }^{\mathrm{a}}$.

\begin{tabular}{|c|c|c|c|c|c|}
\hline \multirow[t]{2}{*}{ Group } & \multirow{2}{*}{$\begin{array}{l}\text { Additives added to the } \\
\text { basal diet }\end{array}$} & \multicolumn{2}{|c|}{ The body weights of lambs } & \multirow{2}{*}{$\begin{array}{l}\text { Body weight gain } \\
(\mathrm{BWG})^{\mathrm{d}}(\%)\end{array}$} & \multirow[t]{2}{*}{ Brain mass ${ }^{g}(g)$} \\
\hline & & $\begin{array}{l}\mathrm{BW}_{\text {initial }} \mathrm{b} \\
(\mathrm{kg})\end{array}$ & $\mathrm{BW}^{\mathrm{c}}(\mathrm{kg})$ & & \\
\hline $\mathrm{RO}^{\mathrm{e}}$ & $3 \%$ RO (RO diet) & $30.7 \pm 3.2$ & $36.3 \pm 3.4$ & $18.5 \pm 1.3^{\mathrm{a}}$ & $115 \pm 8^{a}$ \\
\hline $\mathrm{FO}^{\mathrm{f}}$ & $\begin{array}{l}2 \% \mathrm{RO}, 1 \% \mathrm{FO} \\
\text { (FO diet) }\end{array}$ & $30.6 \pm 2.4$ & $37.7 \pm 2.1$ & $23.4 \pm 1.1^{b}$ & $123 \pm 10^{\mathrm{a}}$ \\
\hline $\mathrm{CA}^{\mathrm{f}}$ & $\begin{array}{l}2 \% \mathrm{RO}, 1 \% \mathrm{FO} \text { and } \\
0.1 \% \mathrm{CA} \text { (CA diet) }\end{array}$ & $30.6 \pm 2.6$ & $37.2 \pm 2.3$ & $21.5 \pm 1.1^{\mathrm{a}}$ & $112 \pm 9^{a}$ \\
\hline $\mathrm{CASeY}^{\mathrm{f}}$ & $\begin{array}{l}2 \% \mathrm{RO}, 1 \% \mathrm{FO}, 0.1 \% \mathrm{CA} \\
\text { and } 0.35 \mathrm{ppm} \text { Se as SeY } \\
\text { (CASeY diet) }\end{array}$ & $30.3 \pm 2.7$ & $36.8 \pm 2.7$ & $21.6 \pm 1.5^{\mathrm{a}}$ & $113 \pm 8^{\mathrm{a}}$ \\
\hline $\mathrm{CASeVI}^{\mathrm{f}}$ & $\begin{array}{l}2 \% \mathrm{RO}, 1 \% \mathrm{FO}, 0.1 \% \mathrm{CA} \\
\text { and } 0.35 \mathrm{ppm} \text { Se as } \\
\text { SeVI (CASeVI diet) }\end{array}$ & $30.3 \pm 3.0$ & $38.5 \pm 3.1$ & $26.8 \pm 1.6^{\mathrm{b}}$ & $119 \pm 8^{\mathrm{a}}$ \\
\hline
\end{tabular}

${ }^{a}$ Results are expressed as means \pm standard deviations (SDs). Mean values in columns having the different superscripts are significantly different at a,b $P<0.05$. Statistical analyses were carried out between groups RO and FO and between groups CA, CASeY and CASeVI;

$\mathrm{b}$ The average initial body weight $(\mathrm{kg})$ of lambs after the 3-week preliminary period;

$\mathrm{c}$ The average body weight $\left(\mathrm{BW}_{35 \text { days }} ; \mathrm{kg}\right)$ of lambs after 35 days of the experimental period;

$\mathrm{d}$ The relative body weight gain of lambs after 35 days of the experimental period; $\mathrm{BWG}, \%=\left[\left(\mathrm{BW}_{35 \text { days }}-\mathrm{BW}_{\text {initial }}\right) \times 100 \%\right] / \mathrm{BW}_{\text {initial }}$;

${ }^{\mathrm{e}}$ For the 3-week preliminary period the lambs were fed the basal diet enriched in $3 \% \mathrm{RO}$;

${ }^{\mathrm{f}}$ For the 3-week preliminary period the lambs were fed the basal diet enriched in $2 \% \mathrm{RO}$ and $1 \%$ FO;

$\mathrm{g}$ The concentration of Se in the brains of lambs fed the CASeY and CASeVI diets were higher than in the brains of lambs fed the diets without addition of SeY or SeVI (i.e. Se concentrations of the lamb brains per unit dry mass: $0.43 \pm 0.01$ and $0.302 \pm 0.007$ ppm, respectively).

In second experiment (Table 2), after the 3-week preliminary period, for 35 days the lambs were fed the FO diet enriched in $0.1 \%$ CA (the CA diet; group CA), the FO diet enriched in $0.1 \% \mathrm{CA}$ and $0.35 \mathrm{ppm} \mathrm{Se}$ as $\mathrm{SeY}$ (the CASeY diet; group $\mathrm{CASeY}$ ) or the $\mathrm{FO}$ diet enriched in $0.1 \% \mathrm{CA}$ and $0.35 \mathrm{ppm}$ Se as SeVI (the CASeVI diet; group CASeVI).

All diets were formulated to be isoenergetic and isonitrogenous. All diets were adjusted weekly and supplied as two equal meals at 07:30 and 16:00 each day to ensure free access to dosed feed. The diet allowance was changed weekly according to body weights of lambs. Animals completely ate served portion meals. All lambs were fed the same mass of freshly prepared diets with the appropriate additives (appropriate amounts of RO, FO, CA, SeY or SeVI were daily added to the concentrate and then vigorously mixed; Table 2). The average daily diet intake was $1.08 \mathrm{~kg}$ per lamb. Fresh drinking water was always available. The lambs were slaughtered at the end of the 35-day experiment (i.e. at 07:00-08:00). After $12 \mathrm{~h}$ of starving, lambs were made unconscious by the intramuscular ration of $\mathrm{xy}$ lazine (2-4 mg $\left.10 \mathrm{~kg}^{-1} \mathrm{BW}\right)$. The whole brains were removed, weighed (Table 2), homogenized and frozen. All brains were stored in sealed tubes at $-32^{\circ} \mathrm{C}$ until chromatographic analyses; each brain sample was analysed separately.

\subsection{Chemicals}

HPLC-grade acetonitrile, methanol and GC-99\%-grade $n$-hexane were purchased from Lab-Scan (Dublin, Ire- land); other reagents were of analytical grade (POCh, Poland). Methyl ester standards of a conjugated linoleic acid (CLA) isomer mixture and all other methyl ester standards of fatty acids, fatty aldehyde standards, cholest4-en-3-one, 5 $\alpha$-cholestane (the internal standard), 2,4dinitrophenylhydrazine, 2,6-di-tert-butyl- $p$-cresol, sodium selenate (SeVI), 1,1,3,3-tetramethoxy propane and $25 \%$ $\mathrm{BF}_{3}$ in methanol were provided by Sigma-Aldrich ( $\mathrm{St}$ Louis, MO, USA). Chloroform, dichloromethane (DCM), methanol, tocopherol standards, cholesterol, $\mathrm{KOH}, \mathrm{NaOH}$, $\mathrm{Na}_{2} \mathrm{SO}_{4}$ and concentrated $\mathrm{HCl}$ were purchased from $\mathrm{POCh}$ (Gliwice, Poland). All other chemicals were of analytical grade and organic solvents were of HPLC grade. Carnosic acid (CA) was purchased from Hunan Geneham Biomedical Technology Ltd. (Changsha Road, Changsha, Hunan, China). Rapeseed oil (RO) and odourless fish oil (FO) were supplied by company AGROSOL (Pacanów, Poland). RO comprised the following main fatty acids ( $\mu \mathrm{g} \mathrm{g}^{-1}$ RO): C14:0 56, C16:0 13091, $c 9 \mathrm{C} 16: 133$, C18:0 5490, c9C18:1 85859, c12C18:1 786, LA 282394, C18:3n3 ( $\alpha$ LNA) 74, C20:0 194, c11C20:1 108, C22:0 430 and $c 15 \mathrm{C} 24: 161$. FO included the following main fatty acids $\left(\mu \mathrm{g} \mathrm{g}^{-1}\right): \mathrm{C} 12: 0$ 82, C14:0 12345, c9C14:1 215, C15:0 477, C16:0 56947, $c 7 \mathrm{C} 16: 1$ 318, $c 9 \mathrm{C} 16: 1$ 420, $\sum \mathrm{C} 16: 2$ 15586, C17:0 493, c9C17:1 193, C18:0 9452, c6C18:1 188, c7C18:1 842, c9C18:1 290592, c12C18:1 15834, c14C18:1 159, LA 114512, $\alpha$ LNA 20968, c11C20:1 24206, c7c9c12c15C18:4 473, c11c14C20:2 2270, c8c11c14C20:3 
258, ArA 304, c8c11c14c17C20:4 607, C22:0 139, c13C22:1 11036, c11C22:1 1704, C20:5n-3 (EPA) 6792, c13c16C22:2 95, c7c10c13c16C22:4 144, c15C24:1 397, C22:5n-3 (DPA) 1560 and DHA 26570 . The meadow hay contained the fol-

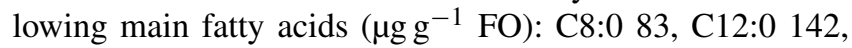
C14:0 239, c9C15:1 131, C16:0 4034, c9C16:1 184, C18:0 459, $c 9$ C18:1 1266, c12C18:1 72, LA 13100, $\alpha$ LNA 4178, C20:0 58, c11C20:1 74, C22:0 101, C24:0 69, c15C24:1 71.

The vitamin and mineral mixture was purchased from POLFAMIX OK (Grodzisk Mazowiecki, Poland); $1 \mathrm{~kg}$ of vitamin and mineral mixture comprised $285 \mathrm{~g}$ calcium, $16 \mathrm{~g}$ phosphorus, $56 \mathrm{~g}$ sodium, $42 \mathrm{mg}$ cobalt as carbonate, $10 \mathrm{mg}$ iodine as iodate, $1 \mathrm{~g}$ iron as sulfate, $6 \mathrm{mg}$ Se as selenite, $0.5 \mathrm{~g}$ copper as sulfate, $5.8 \mathrm{~g}$ manganese as sulfate, $7.5 \mathrm{~g}$ zinc as sulfate; vitamins included A (500000 $\left.\mathrm{IU} \mathrm{kg}^{-1}\right), \mathrm{D} 3$ (125000 IU kg${ }^{-1}$ ), and $\mathrm{E}$ as $\alpha$-tocopherol (25000 IU kg ${ }^{-1}$ ).

The selenized yeast (Se-Saccharomyces cerevisiae) was donated by Sel-Plex (Alltech In., USA). About $83 \%$ of the total Se content of selenized yeast (SeY) represents Se in the form of Se methionine (Se-Met) incorporated into the proteins of Saccharomyces cerevisiae (Czauderna et al., 2009a); the chemical composition of $\mathrm{SeY}$ was presented in a previous publication (Czauderna et al., 2009a).

Water used for the preparation of mobile phases and chemical reagents was prepared using an Elix $^{\mathrm{TM}}$ water purification system (Millipore, Canada). The mobile phases were filtered through a $0.45 \mu \mathrm{m}$ membrane filter (Millipore) and then degassed for 2-3 min in a vacuum with ultrasonication prior to use.

\subsection{Saponification and extraction of fatty aldehydes and CHOL-4-3 from brain hydrolysates}

Fatty aldehydes in homogenized brain samples $(\sim 50 \mathrm{mg})$ were hydrolysed with a mixture of $2 \mathrm{~mL}$ of $2 \mathrm{M} \mathrm{KOH}$ in water and $2 \mathrm{~mL}$ of $1 \mathrm{M} \mathrm{KOH}$ in methanol. Next, $50 \mu \mathrm{L}$ of the internal standard (IS) solution $\left(17 \mathrm{mg} \mathrm{mL}^{-1}\right.$ nonadecanoic acid in chloroform) was added to the obtained mixture. The resulting mixture was flushed with argon $(\mathrm{Ar})$ for $\sim 4 \mathrm{~min}$. The vial was then sealed and the mixture vortexed and heated under $\mathrm{Ar}$ at $95^{\circ} \mathrm{C}$ for $10 \mathrm{~min}$, cooled for $10 \mathrm{~min}$ at room temperature, and sonicated for $10 \mathrm{~min}$. The resulting mixture was protected from the light and stored in the sealed vial under $\mathrm{Ar}$ at $\sim 22^{\circ} \mathrm{C}$ overnight. Next, $3 \mathrm{~mL}$ of water was added to the hydrolysate and the solution was again vortexed. The obtained solution was acidified with $4 \mathrm{M} \mathrm{HCl}$ to $\sim \mathrm{pH} 2$, and free fatty acids were extracted four times with each $3 \mathrm{~mL}$ of DCM. Extraction was repeated four times with each $3 \mathrm{~mL}$ of $n$-hexane. The upper $n$-hexane layer was combined with the DCM layer, and next the resulting organic phase was dried with $\sim 0.1 \mathrm{~g}$ of $\mathrm{Na}_{2} \mathrm{SO}_{4}$. The organic solvents were removed under a stream of $\mathrm{Ar}$ at room temperature. Afterwards the residue was re-dissolved in $0.5 \mathrm{~mL}$ of $n$-hexane, and then $1 \mu \mathrm{L}$ of the resulting solution was injected onto the GC column. The total fatty aldehyde profile in a $1 \mu \mathrm{L}$ sample at a split ratio of $10: 1$ was determined using the column temperature gradient programme. The column was operated at $90^{\circ} \mathrm{C}$ for $10 \mathrm{~min}$, then the temperature programmed at $7^{\circ} \mathrm{C} \mathrm{min}^{-1}$ to $200^{\circ} \mathrm{C}$, held for $21 \mathrm{~min}$, programmed at $10^{\circ} \mathrm{C} \mathrm{min}^{-1}$ to $235^{\circ} \mathrm{C}$, held for $25 \mathrm{~min}$. Helium as the carrier gas operated at a constant pressure $(223.4 \mathrm{kPa})$ and flow rate of $1 \mathrm{~mL} \mathrm{~min}^{-1}$. Injector and MS detector temperatures were maintained at 200 and $240^{\circ} \mathrm{C}$, respectively.

CHOL-4-3 in brain samples was determined after saponification according to Czau-derna et al. (2013). Free CHOL4-3 in processed samples was then quantified using capillary gas chromatography coupled to a quadrupole mass selective detector (Czauderna et al., 2013).

\subsection{Saponification, extraction and preparation of fatty acid methyl esters}

Fatty acids (FAs) in homogenized brain samples were saponified according to Czauderna et al. (2009a) followed by gentle methylations. The base- and acid-catalysed methylations were introduced for preparation of methyl esters of fatty acids (FAMEs) in brain samples (Czauderna et al., 2009a). FAMEs were then quantified using a capillary gas chromatography according to Czauderna et al. (2009a).

\subsection{Gas chromatographic equipment}

The analyses of fatty aldehydes, FAMEs and CHOL-4-3 in brain samples were performed on a SHIMADZU GC-MSQP2010 Plus EI equipped with a BPX70 fused silica capillary column $(120 \mathrm{~m} \times 0.25 \mathrm{~mm}$ i.d. $\times 0.25 \mu \mathrm{m}$ film thickness; SHIM-POL, a quadrupole mass selective detector (Model 5973N) and an injection port. Fatty aldehydes and FAME identifications were validated based on electron impact ionization spectra of fatty aldehydes and FAMEs and compared with authentic fatty aldehydes, CHOL-4-3, and FAME standards and the NIST 2007 reference mass spectra library.

\subsection{Saponification, extraction and analyses of tocopherols, $\mathrm{CHOL}$, its metabolite and MDA in the brain}

Tocopherols and CHOL in homogenized brain samples were quantified using reversed-phase liquid chromatography according to Czauderna et al. (2009b). The MDA concentration in brain samples was determined after saponification followed by derivatization according to Czauderna et al. (2011). Chromatographic analyses of tocopherols, CHOL and derivatized MDA in brain samples were performed using an ultra-fast liquid chromatography system and a photodiode array detector (SHIMADZU, Japan) (Czauderna et al., 2011). 
Table 3. The concentrations ( $\mathrm{mg} \mathrm{g}^{-1}$ ) of fatty acids, indexes of $A^{\mathrm{SFA}}$ (index $A^{\mathrm{SFA}}$ ) and $T^{\mathrm{SFA}}$ (index $T^{\mathrm{SFA}}$ ), and the concentration ratios of $\Sigma$ SFAs to $\Sigma$ FAs, $\Sigma$ PUFAs or $\Sigma$ LPUFAs in the brains of lambs ${ }^{\text {a }}$.

\begin{tabular}{lcc|ccc}
\hline & \multicolumn{2}{c}{ The first experiment } & \multicolumn{3}{c}{ The second experiment } \\
\cline { 2 - 6 } Fatty acids & RO & FO & CA & CASeY & CASeVI \\
\hline C14:0 & $0.125^{\mathrm{a}}$ & $0.093^{\mathrm{b}}$ & $0.097^{\mathrm{a}}$ & $0.118^{\mathrm{a}}$ & $0.123^{\mathrm{a}}$ \\
C16:0 & $3.29^{\mathrm{a}}$ & $2.90^{\mathrm{a}}$ & $2.88^{\mathrm{a}}$ & $3.09^{\mathrm{ab}}$ & $3.42^{\mathrm{b}}$ \\
C18:0 & $13.05^{\mathrm{a}}$ & $2.83^{\mathrm{a}}$ & $2.80^{\mathrm{a}}$ & $3.00^{\mathrm{ab}}$ & $3.33^{\mathrm{b}}$ \\
$\Sigma$ SFAs & $6.72^{\mathrm{a}}$ & $6.03^{\mathrm{b}}$ & $5.97^{\mathrm{a}}$ & $6.48^{\mathrm{ab}}$ & $7.10^{\mathrm{b}}$ \\
$\Sigma$ FAs & $15.6^{\mathrm{a}}$ & $14.3^{\mathrm{a}}$ & $13.5^{\mathrm{a}}$ & $15.4^{\mathrm{ab}}$ & $16.3^{\mathrm{b}}$ \\
$A^{\text {SFA d }}$ & $3.42^{\mathrm{A}}$ & $2.99^{\mathrm{B}}$ & $2.98^{\mathrm{a}}$ & $3.21^{\mathrm{ab}}$ & $3.55^{\mathrm{b}}$ \\
$T^{\text {SFA e }}$ & $6.46^{\mathrm{a}}$ & $5.82^{\mathrm{b}}$ & $5.78^{\mathrm{a}}$ & $6.21^{\mathrm{ab}}$ & $6.88^{\mathrm{b}}$ \\
index $^{\text {SFA f }}$ & $0.467^{\mathrm{a}}$ & $0.438^{\mathrm{b}}$ & $0.470^{\mathrm{a}}$ & $0.448^{\mathrm{a}}$ & $0.465^{\mathrm{a}}$ \\
index $^{\text {SFA g }}$ & $0.334^{\mathrm{a}}$ & $0.296^{\mathrm{b}}$ & $0.298^{\mathrm{a}}$ & $0.325^{\mathrm{b}}$ & $0.310^{\mathrm{ab}}$ \\
$A^{\text {SFA }} / \Sigma n$-3PUFAs & $1,890^{\mathrm{a}}$ & $1.600^{\mathrm{b}}$ & $1.593^{\mathrm{a}}$ & $1.783^{\mathrm{b}}$ & $1,699^{\mathrm{b}}$ \\
$T^{\text {SFA }} / \Sigma n$-3PUFAs & $3.589^{\mathrm{a}}$ & $3.112^{\mathrm{b}}$ & $3.091^{\mathrm{a}}$ & $3.450^{\mathrm{b}}$ & $3.292^{\mathrm{b}}$ \\
$\Sigma$ SFAs $/ \Sigma$ PUFAs & $1.71^{\mathrm{a}}$ & $1.59^{\mathrm{b}}$ & $1.63^{\mathrm{a}}$ & $1.68^{\mathrm{a}}$ & $1.68^{\mathrm{a}}$ \\
$\Sigma$ SFAs $/ \Sigma$ LPUFAs & $1.77^{\mathrm{a}}$ & $1.66^{\mathrm{b}}$ & $1.72^{\mathrm{a}}$ & $1.75^{\mathrm{a}}$ & $1.76^{\mathrm{a}}$ \\
\hline
\end{tabular}

a Mean values in rows having the different superscripts are significantly different at ${ }^{\mathrm{a}, \mathrm{b}} \mathrm{P}<0.05$;

Statistical analyses were carried out between groups RO and FO and between groups CA, CASeY and CASeVI;

b The sum of C8:0, C10:0, C12:0, C14:0, C16:0, C18:0, C20:0, C22:0 and C24:0;

$\mathrm{c}$ The sum of all assayed fatty acids;

$\mathrm{d}$ The atherogenic SFAs $=\mathrm{C} 12: 0, \mathrm{C} 14: 0$ and $\mathrm{C} 16: 0$;

e The thrombogenic SFAs $=\mathrm{C} 14: 0, \mathrm{C} 16: 0$ and $\mathrm{C} 18: 0$;

$\mathrm{f}$ The atherogenic index $=(\mathrm{C} 12: 0+4 \times \mathrm{C} 14: 0+\mathrm{C} 16: 0) /($ MUFAs $+n-6$ PUFAs $+n-3$ PUFAs $)$ (Morán et al., 2013);

$\mathrm{g}$ The thrombogenic index $=(\mathrm{C} 14: 0+\mathrm{C} 16: 0+\mathrm{C} 18: 0) / 0.5 \times$ MUFAs $+0.5 \times n-6$ PUFAs $+3 \times n-$ 3PUFAs $+n$-3PUFAs $/ n$-6PUFAs) (Morán et al., 2013).

\subsection{Statistical analyses}

Statistical analyses were performed using the Statistica software package (StatSoft, Version 10, 2010). Statistical analyses of the effects of dietary additives (FO, CA, SeY and $\mathrm{SeVI}$ ) on the concentration of FAs, tocopherols, CHOL, CHOL-4-3, MDA and fatty aldehydes in brain samples were conducted using the non-parametric Mann-Whitney $U$ test. The results in Table 2 are presented as mean values with the standard deviations (SDs) of six examined lambs $(n=6)$; the results in Tables 3-5 are presented as the means of the individually analysed samples $(n=6)$. Mean values in the columns or rows having the different superscripts are significantly different at ${ }^{\mathrm{a}, \mathrm{b}} P<0.05$ and ${ }^{\mathrm{A}, \mathrm{B}} P<0.01$.

\section{Results and discussion}

The brain is the major control network for the body's functions and abilities, and it enables automatic operation of vital organs; the brain centres control the reproductive system (Wainwright, 2002; Martin et al., 2004). The hypothalamus is a portion of the brain that controls body temperature, hunger, important aspects of parenting and attachment behaviours, thirst, fatigue, sleep, and circadian rhythms; the hypothalamus controls reproductive and immune systems by regulating the secretory activities of the pituitary gland (the hypo-thalamic-pituitary-gonadal axis) (Martin et al., 2004; Vadakkadath Meethal and Atwood, 2005). LPUFAs (like DHA and ArA) are essential components for lamb brain development and physiological functions (Wainwright, 2002; Patterson et al., 2012; Rosa et al., 2013). Considering the above, we study the effects of dietary FO, CA and antioxidants (SeY and SeVI) on oxidative stress and the contents of physiologically important compounds (like LPUFA, tocopherols, fatty aldehydes, cholesterol and its metabolite) in the brain.

\subsection{Effects of the experimental diets on concentrations of fatty acids in the brain}

In the current study, neither macroscopic lesions nor pathological changes were found in the brain as well as other internal organs of lambs fed the experimental diets enriched in $\mathrm{FO}, \mathrm{CA}$ (a phenolic diterpene), $\mathrm{SeY}$ (rich in Se-Met) or SeVI. In fact, diets containing up to $2 \mathrm{mg}$ Se per $\mathrm{kg}$ would not be toxic for ruminants (McDowell et al., 2005; Weiss and Hogan, 2005; Mainville et al., 2009; Krajewska et al., 2012; Eun et al., 2013; Netto et al., 2014). Our current study also indicated that the experimental diets enriched in $0.35 \mathrm{ppm} \mathrm{Se}$ as $\mathrm{SeY}$ or SeVI resulted in a relatively small increase $(P<0.05)$ in the concentration of $\mathrm{Se}$ in the liver $(65-70 \%)$, heart (48-50\%), blood (26-49\%), longissimus dorsi muscle (30- 
Table 4. The concentrations ( $\mathrm{mg} \mathrm{g}^{-1}$ ) of fatty acids, values of $\Delta 9$-desaturase index and ratios of $\sum$ PUFAs, $\sum L P U F A s$ and $\sum n$-3LPUFAs to $\sum$ SFAs or $\sum$ FAs in the brains of lambs ${ }^{\mathrm{a}}$.

\begin{tabular}{|c|c|c|c|c|c|}
\hline \multirow[b]{2}{*}{ Fatty acids } & \multicolumn{2}{|c|}{ The first experiment } & \multicolumn{3}{|c|}{ The second experiment } \\
\hline & RO & FO & $\mathrm{CA}$ & CASeY & CASeVI \\
\hline$\Delta 9$-desaturase index ${ }^{b}$ & $0.538^{\mathrm{a}}$ & $0.530^{\mathrm{a}}$ & $0.494^{\mathrm{a}}$ & $0.534^{b}$ & $0.513^{\mathrm{ab}}$ \\
\hline$c 9 \mathrm{C} 18: 1$ & $3.56^{\mathrm{a}}$ & $3.30^{\mathrm{b}}$ & $2.80^{\mathrm{a}}$ & $3.68^{\mathrm{b}}$ & $3.67^{\mathrm{b}}$ \\
\hline t11C18:1 & $20.027^{\mathrm{a}}$ & $0.020^{\mathrm{b}}$ & $0.021^{\mathrm{a}}$ & $0.020^{\mathrm{a}}$ & $0.022^{\mathrm{a}}$ \\
\hline$\Sigma$ MUFAs & $14.91^{\mathrm{a}}$ & $4.50^{\mathrm{a}}$ & $3.84^{\mathrm{a}}$ & $5.03^{\mathrm{b}}$ & $5.01^{\mathrm{b}}$ \\
\hline LA & $142^{\mathrm{a}}$ & $163^{\mathrm{a}}$ & $192^{\mathrm{a}}$ & $147^{\mathrm{a}}$ & $181^{\mathrm{a}}$ \\
\hline$\alpha$ LNA & $0.0017^{\mathrm{A}}$ & $0.0003^{\mathrm{B}}$ & $0.0013^{\mathrm{A}}$ & $0.0015^{\mathrm{A}}$ & $0.00002^{\mathrm{B}}$ \\
\hline $\mathrm{C} 20: 4 n-6$ & $1.20^{\mathrm{a}}$ & $1.03^{\mathrm{a}}$ & $1.03^{\mathrm{a}}$ & $1.16^{\mathrm{a}}$ & $1.22^{\mathrm{a}}$ \\
\hline DPA & $0.104^{\mathrm{a}}$ & $0.121^{\mathrm{a}}$ & $0.120^{\mathrm{a}}$ & $0.143^{\mathrm{a}}$ & $0.121^{\mathrm{a}}$ \\
\hline DHA & $1.70^{\mathrm{a}}$ & $1.74^{\mathrm{a}}$ & $1.75^{\mathrm{ab}}$ & $1.64^{\mathrm{a}}$ & $1.97^{\mathrm{b}}$ \\
\hline$\Sigma$ PUFAs & $3.94^{\mathrm{a}}$ & $3.80^{\mathrm{a}}$ & $3.66^{\mathrm{a}}$ & $3.85^{\mathrm{ab}}$ & $4.17^{\mathrm{b}}$ \\
\hline$\Sigma n$-6PUFAs & $1.41^{\mathrm{a}}$ & $1.24^{\mathrm{a}}$ & $1.27^{\mathrm{a}}$ & $1.38^{\mathrm{a}}$ & $1.45^{\mathrm{a}}$ \\
\hline$\Sigma n$-3PUFAs & $1.81^{\mathrm{a}}$ & $1.87^{\mathrm{a}}$ & $1.87^{\mathrm{ab}}$ & $1.80^{\mathrm{a}}$ & $2.09^{b}$ \\
\hline$\Sigma$ LPUFAs & $3.79^{\mathrm{a}}$ & $3.63^{\mathrm{a}}$ & $3.47^{\mathrm{a}}$ & $3.71^{\mathrm{a}}$ & $3.99^{\mathrm{a}}$ \\
\hline$\Sigma n$-3LPUFAs & $1.81^{\mathrm{a}}$ & $1.87^{\mathrm{a}}$ & $1.87^{\mathrm{a}}$ & $1.78^{\mathrm{a}}$ & $2.09^{\mathrm{a}}$ \\
\hline$\sum n$-6LPUFAs & $1.98^{\mathrm{a}}$ & $1.77^{\mathrm{b}}$ & $1.60^{\mathrm{a}}$ & $1.93^{\mathrm{b}}$ & $1.90^{\mathrm{b}}$ \\
\hline$\sum n-6 / \Sigma n-3^{c}$ & $0.788^{\mathrm{a}}$ & $0.668^{b}$ & $0.681^{\mathrm{a}}$ & $0.792^{\mathrm{b}}$ & $0.704^{\mathrm{ab}}$ \\
\hline$\sum n-6 \mathrm{~L} / \Sigma n-3 \mathrm{~L}^{\mathrm{d}}$ & $1.097^{\mathrm{a}}$ & $0.947^{\mathrm{b}}$ & $0.855^{\mathrm{a}}$ & $1.084^{\mathrm{b}}$ & $0.909^{\mathrm{a}}$ \\
\hline$\Sigma$ PUFAs $/ \Sigma$ FAs & $0.253^{\mathrm{a}}$ & $0.267^{b}$ & $0.274^{\mathrm{a}}$ & $0.257^{\mathrm{b}}$ & $0.262^{\mathrm{ab}}$ \\
\hline$\Sigma$ LPUFAs $/ \Sigma$ FAs & $0.244^{\mathrm{a}}$ & $0.255^{\mathrm{b}}$ & $0.259^{\mathrm{a}}$ & $0.247^{\mathrm{b}}$ & $0.250^{\mathrm{ab}}$ \\
\hline$\Sigma n-3$ LPUFAs / $\Sigma$ SFAs & $0.269^{\mathrm{a}}$ & $0.310^{\mathrm{b}}$ & $0.317^{\mathrm{a}}$ & $0.280^{\mathrm{b}}$ & $0.301^{\mathrm{ab}}$ \\
\hline$\Sigma n-3$ LPUFAs $/ \Sigma$ FAs & $0.116^{\mathrm{a}}$ & $0.132^{\mathrm{b}}$ & $0.141^{\mathrm{a}}$ & $0.120^{\mathrm{b}}$ & $0.132^{\mathrm{ab}}$ \\
\hline
\end{tabular}

${ }^{\mathrm{a}}$ Mean values in rows having the different superscripts are significantly different at ${ }^{\mathrm{a}, \mathrm{b}} P<0.05$ and

A,B $P<0.01$. Statistical analyses were carried out between groups RO and FO and between groups CA, CASeY and $\mathrm{CASeVI}$;

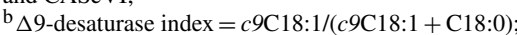

c The ratio of $\Sigma n$-6PUFAs to $\Sigma n$-3PUFAs;

d The ratio of $\Sigma n$-6LPUFAs to $\Sigma n$-3LPUFAs.

$45 \%)$ and biceps femoris muscle (28-36\%) compared with the RO diet; in contrast, the FO or CA diets revealed negligible $(P>0.05)$ impact on the concentration of Se in these tissues in comparison with the RO diet (Ruszczyńska et al., 2016).

As can be seen from results (Table 2), all diets fed to lambs resulted in negligible changes in the brain mass of lambs. On the other hand, our study demonstrated that the supplements added to the diet affect the concentration of SFAs (Table 3) and UFAs (Table 4) in the lamb brain. Our study was especially focused on the concentrations of LPUFAs in the brain. LPUFAs are essential components of the lamb brain (Wainwright, 2002; Patterson et al., 2012; Rosa et al., 2013) and their concentrations remain fairly constant, or change little in the brains of lambs fed the supplemented diets (Table 2). It has been found (Table 4) that the brains of all examined lambs are characterized by the high concentration of LPUFAs ( $\sim 25 \%$ of $\Sigma$ FAs), especially DHA $(11-13 \%$ of $\Sigma F A s)$. In fact, lipids in central nervous tissues of mammals are characterized by a high concentration of DHA, which is especially enriched in amino-phospholipids, serine phosphoglycerides, and ethanol-amine (Schönfeld and Reiser, 2013).
DHA and other $n$-3PUFAs occupy the sn- 2 position of phospholipids, and it has been suggested that the brain has a molecular species requirement for its function (Schönfeld and Reiser, 2013). Indeed, our study showed that DHA in the brain constitutes about $95 \%$ of $\Sigma n$-3PUFA in the lamb brain (Table 4).

\subsubsection{The first experiment}

The results summarized in Table 2 documented that the FO diet increased the body weight gain (BWG) of lambs compared with the RO diet. The FO diet decreased the concentration sum of saturated FAs ( $\sum$ SFAs), including atherogenic $\left(A^{\mathrm{SFA}}\right)$ and thrombogenic $\left(T^{\mathrm{SFA}}\right)$ SFAs in the brain compared with the RO diet (Table 3). As a consequence, the FO diet decreased values of the concentration ratios of $\Sigma$ SFAs to the sum of PUFAs ( $\Sigma$ PUFAs) and the sum of LPUFAs ( $\Sigma$ LPUFAs) in the brain compared with the RO diet. The present results documented that the diet enriched in FO reduced the brain concentration of $\mathrm{C} 14: 0$, which is considered to be 4 times more atherogenic than the other SFAs (like C12:0 or C16:0) (Pikul et al., 2008). The FO diet can prevent atherosclerosis (i.e. the deposition of atheromas) and throm- 
Table 5. The concentrations of cholesterol, CHOL-4-3, tocopherols (T), MDA, fatty aldehydes and values of PUFA peroxidation index ${ }^{\mathrm{a}}$ in the brains of lambs ${ }^{b}$.

\begin{tabular}{|c|c|c|c|c|c|}
\hline \multirow[b]{2}{*}{ Specification } & \multicolumn{2}{|c|}{ The first experiment } & \multicolumn{3}{|c|}{ The second experiment } \\
\hline & RO & FO & CA & CASeY & CASeVI \\
\hline CHOL, $\mu \mathrm{g} \mathrm{g}^{-1}$ & $467^{\mathrm{a}}$ & $410^{\mathrm{a}}$ & $407^{\mathrm{a}}$ & $397^{\mathrm{a}}$ & $380^{\mathrm{a}}$ \\
\hline CHOL-4-3 $\mu \mathrm{g} \mathrm{g}^{-1}$ & $68^{\mathrm{a}}$ & $61^{\mathrm{a}}$ & $31^{\mathrm{a}}$ & $101^{\mathrm{b}}$ & $110^{\mathrm{b}}$ \\
\hline$\delta \mathrm{T}, \mu \mathrm{g} \mathrm{g}^{-1}$ & $2.1^{\mathrm{a}}$ & $2.9^{\mathrm{a}}$ & $1.2^{\mathrm{a}}$ & $1.3^{\mathrm{a}}$ & $1.40^{\mathrm{a}}$ \\
\hline$\gamma \mathrm{T}, \mu \mathrm{g} \mathrm{g}^{-1}$ & $2.7^{\mathrm{a}}$ & $2.6^{\mathrm{a}}$ & $1.5^{\mathrm{a}}$ & $1.8^{\mathrm{ab}}$ & $2.2^{\mathrm{b}}$ \\
\hline$\alpha \mathrm{T}, \mu \mathrm{gg}^{-1}$ & $4.3^{\mathrm{a}}$ & $4.1^{\mathrm{a}}$ & $3.7^{\mathrm{a}}$ & $3.8^{\mathrm{a}}$ & $3.2^{\mathrm{a}}$ \\
\hline$\alpha \mathrm{TAc}, \mu \mathrm{g} \mathrm{g}^{-1}$ & $2.3^{\mathrm{a}}$ & $2.2^{\mathrm{a}}$ & $2.1^{\mathrm{a}}$ & $2.9^{\mathrm{b}}$ & $3.2^{\mathrm{b}}$ \\
\hline$\Sigma \alpha \mathrm{T}^{\mathrm{c}} \mu \mathrm{g} \mathrm{g}^{-1}$ & $6.6^{\mathrm{a}}$ & $6.3^{\mathrm{a}}$ & $5.7^{\mathrm{a}}$ & $6.7^{\mathrm{a}}$ & $6.4^{\mathrm{a}}$ \\
\hline$\Sigma \mathrm{Ts}^{\mathrm{d}}{ }^{\mu} \mu \mathrm{gg}^{-1}$ & $11.4^{\mathrm{a}}$ & $11.8^{\mathrm{a}}$ & $8.5^{\mathrm{a}}$ & $9.1^{\mathrm{a}}$ & $10.1^{\mathrm{a}}$ \\
\hline MDA, $\operatorname{ng~g}^{-1}$ & $8.93^{\mathrm{a}}$ & $9.63^{\mathrm{a}}$ & $10.23^{\mathrm{a}}$ & $9.81^{\mathrm{ab}}$ & $8.66^{\mathrm{b}}$ \\
\hline $\mathrm{MDA}_{\text {index }}, \mathrm{ng} / \mathrm{mg}$ & $2.27^{\mathrm{a}}$ & $2.54^{b}$ & $2.79^{\mathrm{a}}$ & $2.55^{\mathrm{a}}$ & $2.07^{\mathrm{b}}$ \\
\hline \multicolumn{6}{|c|}{ Fatty aldehydes, $\mu \mathrm{g} \mathrm{g}^{-1}$} \\
\hline AL-C10:0 & $96^{\mathrm{a}}$ & $70^{\mathrm{b}}$ & $56^{\mathrm{a}}$ & $70^{\mathrm{a}}$ & $74^{\mathrm{a}}$ \\
\hline AL-C12:0 & $154^{\mathrm{a}}$ & $116^{\mathrm{b}}$ & $107^{\mathrm{a}}$ & $101^{\mathrm{a}}$ & $125^{\mathrm{a}}$ \\
\hline AL-C14:0 & $625^{\mathrm{a}}$ & $562^{\mathrm{a}}$ & $494^{\mathrm{a}}$ & $662^{\mathrm{b}}$ & $815^{\mathrm{c}}$ \\
\hline AL-C16:0 & $49^{\mathrm{a}}$ & $49^{\mathrm{a}}$ & $39^{\mathrm{a}}$ & $55^{\mathrm{b}}$ & $67^{\mathrm{b}}$ \\
\hline AL-C18:0 & $984^{\mathrm{a}}$ & $911^{\mathrm{a}}$ & $894^{\mathrm{a}}$ & $978^{\mathrm{a}}$ & $1396^{\mathrm{b}}$ \\
\hline AL- $c 9 \mathrm{C} 18: 1$ & $480^{\mathrm{a}}$ & $397^{\mathrm{a}}$ & $330^{\mathrm{a}}$ & $474^{\mathrm{b}}$ & $541^{\mathrm{b}}$ \\
\hline AL-c11C18:1 & $431^{\mathrm{a}}$ & $342^{\mathrm{a}}$ & $288^{\mathrm{a}}$ & $395^{\mathrm{b}}$ & $469^{b}$ \\
\hline$\sum \mathrm{ALs}^{\mathrm{e}}$ & $2820^{\mathrm{a}}$ & $2446^{\mathrm{a}}$ & $2206^{\mathrm{a}}$ & $2735^{\mathrm{a}}$ & $3487^{b}$ \\
\hline
\end{tabular}

a PUFA peroxidation index: $\mathrm{MDA}_{\text {index }}\left(\mathrm{ng} \mathrm{mg}^{-1}\right)=\left[\mathrm{MDA}\left(\mathrm{ng} \mathrm{g}^{-1}\right)\right] /\left[\sum \mathrm{PUFAs}\left(\mathrm{mg} \mathrm{g}^{-1}\right)\right]$.

$\sum$ PUFAs - the concentration sum of PUFAs in the brain;

${ }^{\mathrm{b}}$ Mean values in rows having the different superscripts are significantly different at ${ }^{\mathrm{a}, \mathrm{b}} P<0.05$.

Statistical analyses were carried out between groups RO and FO and between groups CA, CASeY and CASeVI;

c The concentration sum of $\alpha$-tocopherol $(\alpha \mathrm{T})$ and $\alpha$-tocopheryl acetate $(\alpha \mathrm{TAc})$;

d The concentration sum of $\delta \mathrm{T}, \gamma \mathrm{T}, \alpha \mathrm{T}$ and $\alpha \mathrm{TAc}$

e The concentration sum of all assayed fatty aldehydes.

bosis in the brain (i.e. the formation or presence of a blood clot in cerebral vessels; Ogata et al., 2011).

A better evaluation of the functional effects of dietary supplements on atherosclerosis and thrombosis may be given by the indexes of atherogenicity (index $A^{\mathrm{SFA}}$ ) and thrombogenicity (index $T^{\mathrm{SFA}}$ ) (Pikul et al., 2008; Morán et al., 2013). These indexes were calculated using concentrations of $A^{\mathrm{SFA}}$ and $T^{\mathrm{SFA}}$ as well as $n$-3PUFAs, $n$-6PUFAs and monounsaturated FAs (MUFAs) (Table 3 ); $\operatorname{index}^{\mathrm{SFA}}$ is defined as the relationship between the pro-atherogenic SFAs $\left(A^{\mathrm{SFA}}\right)$ and anti-atherogenic FAs (MUFAs, $n$-6PUFAs and $n$-3PUFAs). index $T^{\mathrm{SFA}}$ is defined as the relationship between the prothrombogenetic SFAs ( $T^{\mathrm{SFA}}$ ), the anti-thrombogenetic fatty acids (MUFAs, $n$-6PUFAs and $n$-3PUFAs) and the ratio of $n$ 3PUFAs to $n$-6PUFAs; a high $n$-6PUFAs over $n$-3PUFA ratio is thrombogenic (Pikul et al., 2008; Garaffo et al., 2011). As expected, our study indicated that the FO diet also decreased $\operatorname{index} A^{\mathrm{SFA}}$ and index $T^{\mathrm{SFA}}$ as well as the concentration ratios of $A^{\mathrm{SFA}}$ and $T^{\mathrm{SFA}}$ to $\Sigma n$-3PUFA in the brain compared with the RO diet (Table 3 ). The $A^{\mathrm{SFA}} / \Sigma n$-3PUFA and $T^{\mathrm{SFA}} / \Sigma n$ 3PUFA ratios are the relationship between $A^{\mathrm{SFA}}$ and $T^{\mathrm{SFA}}$ as well as $n$-3PUFAs; $n$-3PUFAs play of critical roles in preventing atherosclerosis and thrombosis (Pikul et al., 2008; Garaffo et al., 2011). Thus, current study and other investigations (Pikul et al., 2008; Garaffo et al., 2011) indicated that, in contrast to the RO diet, the FO diet (rich in $n$-3LPUFA) reduced the risk of the pathological changes in cerebral vessels (i.e. changes resulting in athero-thrombotic stroke or hypertension) (Ogata et al., 2011); so, the concentrations of $A^{\text {SFA }}$ and $T^{\mathrm{SFA}}$ as well as the values of index $A^{\mathrm{SFA}}$ and index $T^{\mathrm{SFA}}$ (Table 3 ) are the powerful predictors of a risk for arteriosclerotic cerebral vessel changes (e.g. athero-thrombotic stroke).

The diet containing only RO (rich in LA) stimulated the desaturation and elongation of $n$-6PUFAs (like LA) to $n$ 6LPUFAs (i.e. precursors of eicosanoids involved in various pathological processes involving inflammatory conditions such as atherosclerosis, obesity, and Alzheimer's disease). Therefore, the concentration of LA was numerically lower $(P=0.068)$ in the brains of lambs fed the RO diet than in the brains of lambs fed the FO diet (Table 4). Consequently, the RO diet increased the concentrations of pro-inflammatory precursors ( $n$-6LPUFAs) and 
the $\sum n$-6PUFAs / $\sum n$-3PUFAs and $\sum n$-6 LPUFAs / $\sum n$ 3LPUFA ratios in the brain. Therefore, we argued that the RO diet increased the risk of diseases in the ruminant brain as the high concentrations of $A^{\mathrm{SFA}}, T^{\mathrm{SFA}}$ and the high $n$-6PUFAs over $n$-3PUFA ratio (Tables 3 and 4 ) are hypercholesterolemic, atherogenic and thrombogenic (Pikul et al., 2008; Garaffo et al., 2011; Orth and Bellosta, 2012). On the other hand, the FO diet reduced the risk of atherosclerosis, thrombosis and reduced inflammation in the lamb brain as this diet decreased the $\Sigma n$-6PUFAs / $\Sigma n$ 3PUFA ratio, the concentrations of $A^{\mathrm{SFA}}, T^{\mathrm{SFA}}$ and increased the ratios of $\Sigma$ PUFAs / $\Sigma F A s, \Sigma$ LPUFAs $/ \Sigma F A s$, $\Sigma n$-3LPUFAs / $\Sigma$ SFAs and $\Sigma n$-3LPUFAs / $\Sigma$ FAs (Table 4) compared with the RO diet. The addition of FO to the diet reduced the concentration of $\sum n$-6LPUFAs and the ratio of $\sum n$-6LPUFAs to $\sum n$-3LPUFAs in the brain compared with the RO diet. Therefore, we argued that dietary FO, rich in $n$-3PUFAs, decreased the capacity of the desaturation and elongation of $n$-6PUFAs (e.g. LA) to their $n-6$ long-chain anabolites (i.e. $n$-6LPUFAs) (Table 4). In fact, $n$-3PUFAs usually have higher affinity than $n$-6PUFAs for the elongation and desaturation enzymes in mammal tissues (Patterson et al., 2012).

\subsubsection{The second experiment}

It has been found that the CASeVI diet increased the body weight gain (BWG) of lambs compared with the CA and CASeY diets (Table 2). The diets enriched in FO and CA, irrespective of the presence of $\mathrm{SeY}$ or $\mathrm{SeVI}$, affected the concentrations of fatty acids in the lamb brains (Tables 3 and 4). Indeed, concentrations of fatty acids in the brain are effectively altered by the concentrations of FAs and antioxidants in a diet, and with life stage, increasing with development and decreasing with aging (Niedźwiedzka et al., 2006; Uauy and Dangour, 2013). As can be seen from the results in Table 3, the CASeVI diet increased the concentration of $\sum$ SFAs, including $A^{\mathrm{SFA}}$ and $T^{\mathrm{SFA}}$, in the brain compared with the CA diet. On the other hand, the CASeVI diet only numerically increased $(P>0.05)$ the concentrations of $\sum$ SFAs as well as C16:0, C18:0, $A^{\mathrm{SFA}}$ and $T^{\mathrm{SFA}}$ in the brain as compared with the CASeY diet. The CASeY diet revealed only numerical effects (numerically increased) on the concentrations of these fatty acids in the brain compared with the CA diet. Concomitantly, the CASeY and CASeVI diets increased the values of the $A^{\mathrm{SFA}} / \Sigma n-3 \mathrm{PUFA}$ and $T^{\mathrm{SFA}} / \Sigma n$ 3PUFA ratios in the brain compared with the CA diet. Our study showed that the CASeY diet increased the value of ${ }_{\text {index }} T^{\mathrm{SFA}}$ in the brain compared with the CA diet.

Thus, the present data are in agreement with our previous investigations in which diets enriched in SeVI stimulated the accumulation of $\sum \mathrm{SFAs}$, including $A^{\mathrm{SFA}}$ and $T^{\mathrm{SFA}}$, in subcutaneous fat tissue and blood plasma of lambs (Niedźwiedzka et al., 2008). Considering the above facts, we argued that the diet with SeY and especially SeVI (groups
CASeY and CASeVI) increased the risk of the pathological changes in cerebral vessels (Garaffo et al., 2011; Ogata et al., 2011). Chronic ingestion of SFAs results in blood-brain barrier dysfunction and significant delivery into the brains of plasma proteins. Moreover, it is well known that among the saturated fatty acids, C12:0, C16:0 and especially C14:0 are recognized as health risk factors (resulting in atherothrombotic stroke, hypertension or coronary diseases) (Ogata et al., 2011; Morán at al., 2013; Schönfeld and Reiser, 2013).

The current study showed that the CASeY diet more efficiently increased the capacity of $\Delta 9$-desaturation (the $\Delta 9$ desaturase index) in the brain than the CA diet. Moreover, the concentration of $c 9 \mathrm{C} 18: 1$ is higher in the brains of lambs fed the CASeY and CASeVI diets compared with lambs fed the CA diet (Table 4). Indeed, the CA diet decreased the concentration of $c 9 \mathrm{C} 18: 1$ in the brain, resulting in a drop of the concentration of $\sum$ MUFAs in the brain compared with the $\mathrm{CASeY}$ and CASeVI diets.

The present study showed that the CASeY and CASeVI diets stimulated the accumulation of $c 9 \mathrm{C} 18: 1$ (the product of $\Delta 9$-desaturation of C18:0), while the CASeVI diet also increased the concentration of $\sum$ PUFAs in the brain compared with the CA and CASeY diets (Table 4). Thus, current investigations are consistent with our previous studies in which dietary SeVI increased the capacity of $\Delta 9$-desaturation in adipose tissues and decreased the yield of fatty acid catabolism in adipose tissues of rats (Czauderna et al., 2003). Thus, the CASeVI diet increased the concentration of $\sum F A s$ (including $\sum$ SFAs, $\sum$ MUFAs and $\sum$ PUFAs) in the brain compared with the CA diet (Tables 3 and 4).

We documented that the diets enriched in $\mathrm{SeY}$ or $\mathrm{SeVI}$ stimulated the capacity of desaturation and elongation enzymes of $n$-6PUFAs to $n$-6LPUFAs in the brain compared with the CA diet (Table 4). Therefore, the CASeY and CASeVI diets more efficiently increased the accumulation of $n$-6LPUFA in the brain than the CA diet. Moreover, the diet including $\mathrm{SeY}$ (rich in Se-Met) increased the ratios of $\sum n$-6PUFAs / $\sum n$-3PUFAs and $\sum n$-6LPUFAs / $\sum n$ 3LPUFAs in the brain, while it reduced the ratios of $\sum n$ 3LPUFAs / $\sum$ SFAs and $\sum n$-3 LPUFAs / $\sum$ FAs in the brain compared with the CA diet. Therefore, we suggest that SeVI and especially $\mathrm{SeY}$ added to the diet modify an impact of $n$-3PUFAs derived from FO on the capacity of the desaturation and elongation enzymes of $n$-6PUFAs to $n$-6LPUFAs in the brain. We argued that SeVI and especially SeY added to the diet increased the affinity of $n$-6PUFAs for the elongation and desaturation enzymes in the brain, whereas it reduced the affinity of $n$-3PUFA for these enzymes in the brain compared with the CA diet.

Considering the above facts, we suggested that the CA diet more efficiently improved brain functions as the concentration of $\Sigma n$-6LPUFAs (long-chain anabolites of LA) and the $A^{\mathrm{SFA}} / \sum n$-3PUFAs and $T^{\mathrm{SFA}} / \sum n$-3PUFA ratios are lower in the brain of lambs fed the CA diet than in the brains of lambs fed the CASeY and CASeVI diets. In fact, cyclooxy- 
genases and lipoxygenases can convert $n$-6LPUFAs (like ArA) to the 2-series of prostaglandins, the 2-series of thromboxanes, and the 4-series of leukotrienes; these eicosanoids are involved in various pathological processes involving inflammatory conditions such as atherosclerosis, obesity, and Alzheimer's disease (Wainwright, 2002; Azad et al., 2011).

\subsection{Effects of the experimental diets on concentrations of $\mathrm{CHOL}, \mathrm{CHOL}-4-3$, tocopherols and aldehydes in the brain}

CHOL is vital to normal physiological functions of the brain (Orth and Bellosta, 2012); CHOL in the brain is primarily derived by de novo synthesis. Excess CHOL in the brain can lead to many signalling events via cholesterol metabolites, antioxidant processes and pro-inflammatory mediators. Numerous studies showed that alternation in CHOL biosynthesis and its degradation influences higher-order brain functions (Orth and Bellosta, 2012). Considering the above fact, we study effects of the diets enriched in FO, CA or Se (as $\mathrm{SeY}$ or $\mathrm{SeVI}$ ) on the concentration of CHOL and its metabolite (CHOL-4-3) in the lamb brain.

\subsubsection{The first experiment}

The effects of the FO diet on the concentrations of CHOL, CHOL-4-3, tocopherols and MDA in the brains of lambs were rather small compared with the RO diet, but some numerical effects of the FO diet on the concentrations of CHOL, CHOL-4-3 and MDA in the brain were observed (Table 5). In comparison with the RO diet, the FO diet numerically decreased the concentrations of CHOL (the statistical tendency: $P=0.087)$ and CHOL-4-3 $(P=0.15)$ and numerically increased the concentration of MDA (the statistical tendency: $P=0.097)$ in the brain. Interestingly, the diet enriched in FO (rich in LPUFA) increased the value of PUFA peroxidation index $\left(\mathrm{MDA}_{\text {index }}\right)$ in the brain compared with the RO diet. So, we argued that a better evaluation of the functional effects of dietary supplements on the capacity of lipid peroxidation may be given by $\mathrm{MDA}_{\text {index }}$. Indeed, this index was calculated using concentration of MDA (the product of PUFA peroxidation) and PUFAs (i.e. the substrates which react with radicals). The yield of MDA formation depends upon the concentration of PUFAs as well as the chemical form of an antioxidant (Czauderna et al., 2011). Based on the value of $\mathrm{MDA}_{\text {index }}$, we argued that the FO diet increased the yield of PUFA peroxidation in the brain compared with the RO diet.

Fatty aldehydes are present in considerable quantity in the lipid fractions of muscles and the brain and may be intermediates in lipid metabolism (Stadelmann-Ingrand et al., 2004; Dannenberger et al., 2006). Thus, we investigate the effect of the RO and FO diets on the abundance of fatty aldehydes in the brain (Table 5). Our study documented that the FO diet reduced the concentrations of AL-C10:0 and AL-C12:0 in the brain compared with the RO diet. The effects of the FO diet on the concentrations of longer chain fatty aldehydes (AL-C14:0, AL-C16:0 and AL-C18:0) and unsaturated fatty aldehydes (AL-c9C18:1 and AL-c1lC18:1) in the brain were rather small compared with the RO diet, but numerical effects of the FO diet on the concentrations of these aldehydes were observed (Table 5); the FO diet numerically decreased $(P>0.05)$ the concentrations of these aldehydes in the brain compared with the RO diet. Therefore, we suggest that the diet enriched in FO (rich in LPUFA) stimulated the catabolism yield of fatty aldehydes (intermediates in lipid metabolism) in the brain compared with the RO diet. Concomitantly, the FO diet more effectively increased PUFA peroxidation (i.e. $\mathrm{MDA}_{\text {index }}$ ) in the brain than the diet with only $\mathrm{RO}$ (poor in LPUFA).

\subsubsection{The second experiment}

It has been found that $\mathrm{SeY}$ or especially SeVI added to the diet stimulated CHOL metabolism to CHOL-4-3 compared with the $\mathrm{CA}$ diet. As a consequence, the concentration of CHOL-4-3 is higher in the brains of lambs fed the CASeY and CASeVI diets than the CA diet (Table 5). Concomitantly, our study shows that the high concentration of CHOL-4-3 in the brains of lambs fed the CASeVI diet implicates the higher increase of the BWG of lambs (Table 2) than the CA and $\mathrm{CASeY}$ diets.

Animal studies documented the importance of dietary tocopherols to the healthy functioning of the brain, including protection against lipid peroxidation, DNA damage and neuron loss (Lu et al., 2015; Morris et al., 2015). Therefore, we examine the impact of the diets enriched in $\mathrm{Se}$ (as SeY and SeVI) on the concentrations of tocopherols in the brain (Table 5). Concerning tocopherols, no significant differences were observed between the $\mathrm{CA}, \mathrm{CASeY}$ and $\mathrm{CASeVI}$ diets in the concentrations of $\delta$-tocopherol $(\delta \mathrm{T}), \alpha$-tocopherol $(\alpha \mathrm{T})$ and the sums of $\alpha \mathrm{T}$ and $\alpha$-tocopheryl acetate $(\Sigma \alpha \mathrm{T})$ and all assayed tocopherols ( $\Sigma \mathrm{Ts}$ ) in the brain. On the contrary, the $\mathrm{CASeY}$ and CASeVI diets resulted in increasing the concentration of $\alpha$-tocopheryl acetate ( $\alpha \mathrm{TAc}$ ) in the brain compared with the CA diet. Moreover, feeding the CASeVI diet resulted in an increase in the concentration of $\gamma$-tocopherol $(\gamma \mathrm{T})$ in the brain compared with the CA diet. Unlike $\alpha \mathrm{T}$, $\gamma \mathrm{T}$ is a potent defender against disease-provoking species in the mammal body known as reactive nitrogen oxides; $\gamma \mathrm{T}$ has been found to decrease inflammation, promote factors that guard against certain cancers, and activate genes involved in protecting against Alzheimer's disease (Lu et al., 2015; Morris et al., 2015). $\gamma \mathrm{T}$ is even superior than $\alpha \mathrm{T}$ in the protection of mammal tissues from damage by some specific free radicals (e.g. peroxynitrite or $\mathrm{NO}_{x}$ ), due to a stable nitro-adduct formed in its unsubstituted position on chromanol ring (Lu et al., 2015).

In the present dietary study, the CASeVI diet decreased the concentration of MDA in the brain compared with the 
CA diet. Moreover, the diet containing SeVI more efficiently reduced the value of $\mathrm{MDA}_{\text {index }}$ in the brain than the $\mathrm{CA}$ and CASeY diets. These results reinforce our suggestions that SeVI is more efficiently utilized for biosynthesis of antioxidative proteins containing Se cysteine (like glutathione peroxidases) than dietary SeY (rich in Se-Met) (Tapiero et al., 2003; Navarro-Alarcon and Cabrera-Vique, 2008). Based on the above observations, we suggest that the diet enriched in SeVI improved brain functions as decreased oxidative stress in brain tissues as well as increased the concentration of $\gamma \mathrm{T}$, which has excellent antiinflammatory, antineoplastic and natriuretic functions (Lu et al., 2015).

Interestingly, the concentration of MDA and the value of $\mathrm{MDA}_{\text {index }}$ in the brains of lambs from group CASeY is similar to the concentration of MDA and the value of $\mathrm{MDA}_{\text {index }}$ in the brains of lambs fed the FO diet (i.e. the diet without antioxidant). Therefore, we suggest that simultaneous dosage of $\mathrm{SeY}$ and CA (the CASeY diet) has negligible impact on the yield of PUFA peroxidation as well as $\mathrm{MDA}_{\text {index }}$ in the brain compared with the FO diet.

We also investigate effects of the diets enriched in FO, $\mathrm{CA}$ without or with $\mathrm{Se}$ treatments (as $\mathrm{SeY}$ or $\mathrm{SeVI}$ ) on the abundance of fatty aldehydes in the lamb brain (Table 5). Our results indicated that the diet enriched in the CASeY and CASeVI diets increased the concentrations of AL-C14:0, AL-C16:0 and unsaturated fatty aldehydes (i.e. AL-c 9 C18:1 and AL-c11C18:1) in the brain compared with the CA diet. Moreover, the diet with SeVI more efficiently stimulated the accumulation of AL-C14:0, AL-C18:0 and the concentration sum of all assayed fatty aldehydes ( $\Sigma$ ALs) in the brain compared with the CA and CASeY diets.

Considering the above results, we suggest that the diet enriched in SeVI reduced the catabolism yield of fatty aldehydes (intermediates in lipid metabolism) in the brain compared with the CA and SeY diets. Indeed, aldehydes are produced during decomposition of hydroperoxides of lipid PUFAs following a reaction of peroxidation; MDA is the end product of lipid PUFA peroxidation (Czauderna et al., 2011; Albert et al., 2013). SeVI added to the diet is the suitable substrate for the biosynthesis Se cysteine containing enzymes, which play important roles in detoxification of reactive oxygen species and reactive nitrogen species, and antioxidant defence mechanisms in the mammal body (Tapiero et al., 2003; Tinggi, 2003; Navarro-Alarcon and Cabrera-Vique, 2008). On the other hand, SeY (rich in Se-Met) added to the diet stimulated the biosynthesis of mainly Se-Met containing proteins, which are not considered anti-oxidative Se enzymes (Navarro-Alarcon and Cabrera-Vique, 2008).

Detailed analyses of the concentrations of $\Sigma F A s$ (Table 3) and $\Sigma$ ALs (Table 5) in the brains of lambs fed all examined diets (the first and second experiment) documented that there is a positive correlation $(r=0.941)$ between with the concentrations of $\Sigma F A$ s and $\Sigma$ ALs in the brain. Therefore, this confirms our suggestion that the biosynthesis yield of fatty aldehydes positively correlated with the concentration of fatty acids in the brain. In fact, fatty aldehydes from fatty acid precursors can occur using carboxylic acid reductase (i.e. a versatile enzyme for conversion of fatty acids into fatty aldehydes) (Kunjapur and Prather, 2015).

\section{Conclusions}

The main novelty of our studies was to investigate the influence of the organic and inorganic form of Se added to the diet including CA and FO on the concentration of FAs, CHOL, its metabolite, tocopherols, MDA and fatty aldehydes in the lamb brain. The CASeY diet showed different impact on the concentrations of FAs, CHOL, CHOL-4-3, tocopherols, MDA and fatty aldehydes in the brain compared with the CA and CASeVI diets. For example, the CASeVI diet reduced the oxidative stress in the brain and increased the concentrations of $\gamma \mathrm{T}$ and $\Sigma$ ALs compared with the CA and CASeY diets.

We argued that our studies provide useful information for nutritionists carrying out further investigations aimed at improving farm-animal health, the growth performance, the reproductive system (by regulating the secretory activities of the pituitary gland) and the nutritional quality of feed. Indeed, physiologically, the function of the brain is to exert centralized control over the other internal organs and tissues of ruminants.

Acknowledgements. This study was in part supported by the National Science Centre (NCN): grant no. 2013/09/B/NZ9/00291 and by the statutory funds from the Kielanowski Institute of Animal Physiology and Nutrition, PAS, Jabłonna, Poland (project no. II.1; 2015).

Edited by: M. Mielenz

Reviewed by: three anonymous referees

\section{References}

Albert, B. B., Cameron-Smith, D., Hofman, P. L., and Cutfield, W. S.: Oxidation of marine omega-3 supplements and human health, Bio. Med. Research International, 2013, 464921, doi:10.1155/2013/464921, 2013.

Azad, N., Rasoolijazi, H., Joghataie, M. T., and Soleimani, S.: Neuroprotective effects of carnosic acid in an experimental model of alzheimer's disease in rats, Cell J., 13, 39-44, 2011.

Chen, C. T., Liu, Z., and Bazinet, R.: Rapid de-esterification and loss of eicosapentaenoic acid from rat brain phospholipids: an intracerebroventricular study, J. Neurochem., 116, 363-373, 2011.

Czauderna, M., Kowalczyk, J., Wąsowska, I., Niedźwiedzka, K. M., and Pastuszewska, B.: The effects of selenium and conjugated linoleic acid (CLA) isomers on fatty acid composition, CLA isomer content in tissues, and growth of rats, J. Anim. Feed Sci., 12, 865-881, 2003.

Czauderna, M., Kowalczyk, J., Niedźwiedzka, K. M., Leng, L., and Cobanova, K.: Dietary selenized yeast and CLA isomer mixture 
affect fatty- and amino acid concentrations in the femoral muscles and liver of rats, J. Anim. Feed Sci., 18, 348-361, 2009a.

Czauderna, M., Kowalczyk, J., and Niedźwiedzka, K. M.: Simple HPLC analysis of tocopherols and cholesterol from specimens of animal origin, Chem. Anal.-Warsaw, 54, 203-214, $2009 \mathrm{~b}$.

Czauderna, M., Kowalczyk, J., and Marounek, M.: The simple and sensitive measurement of malondialdehyde in selected specimens of biological origin and some feed by reversed phase high performance liquid chromatography, J. Chromatogr., 879, 22512258, 2011.

Czauderna, M., Marounek, M., Duskova, D., and Kowalczyk, J.: The sensitive and simple measurement of underivatized cholesterol and its oxygen derivatives in biological materials by capillary gas-chromatography coupled to a mass-selective detector, Acta Chromatograph., 25, 655-667, 2013.

Dannenberger, D., Lorenz, S., Nuernberg, G., Scollan, N., Ender, K., and Nuernberg, K.: Analysis of fatty aldehyde composition, including 12-methyltridecanal, in plasmalogens from longissimus muscle of concentrate- and pasture-fed bulls, J. Agr. Food Chem., 54, 182-188, 2006.

Eun, J.-S., Davis, T. Z., Vera, J. M., Miller, D. N., Panter, K. E., and ZoBell, D. R.: Addition of high concentration of inorganic selenium in orchardgrass (Dactylis glomerata L.) hay diet does not interfere with microbial fermentation in mixed ruminal microorganisms in continuous cultures, Prof. Anim. Sci., 29, 3945, 2013.

Garaffo, M. A., Vassallo-Agius, R., Nengas, Y., Lembo, E., Rando, R., Maisano, R., Dugo, G., and Giuffrida, D.: Fatty acids profile, atherogenic (IA) and thrombogenic (IT) health lipid indices, of raw roe of blue fin tuna (Thunnus Thynnus L.) and their salted product "Bottarga", Food Nutr. Sci., 2, 736-743, 2011.

Han, F., Chen, D., Yu, B., and Luo, W.: Effects of different selenium sources and on serum biochemical parameters and tissue selenium retention in rats, Front. Agric. China, 3, 221-225, 2009.

Jordan, M. J., Lax, V., Rota, M. C., Loran S., and Sotomayor, J. A.: Effect of the phenological stage on the chemical composition, and antimicrobial and antioxidant properties of Rosmarinus officinalis $L$. essential oil and its polyphenolic extract, Ind. Crop. Prod., 48, 144-152, 2013.

Krajewska, K. A., Rozbicka-Wieczorek, A. J., Kowalczyk, J., and Czauderna, M.: Dietary linseed oil and selenate affect the concentration of fatty acids and selenium in the spleen, pancreas, and kidneys of lambs, J. Anim. Feed Sci., 21, 285-301, 2012.

Kunjapur, A. M. and Prather, K. L. J.: Microbial engineering for aldehyde synthesis. Minireview, Appl. Environ. Microb., 81, 1892-1901, 2015.

Lee, Y.-J. and Jenkins, T. C.: Identification of enriched conjugated linoleic acid isomers in cultures of ruminal microorganisms after dosing with $1-{ }^{13} \mathrm{C}$-linoleic acid, J. Microbiol., 49, 622-627, 2011

Lu, D., Yang, Y., Li, Y., and Sun, C.: Analysis of tocopherols and tocotrienols in pharmaceuticals and foods: a critical review, Curr. Pharma. Anal., 11, 66-78, 2015.

Mainville, A. M., Odongo, N. E., Bettger, W. J., McBride, B. W., and Osborne, V. R.: Selenium uptake by ruminal microorganisms from organic and inorganic sources in dairy cows, Can. J. Anim. Sci., 89, 105-110, 2009.

Martin, G. B., Milton, J. T. B., Davidson, R. H., BancheroHunzicker, G. E., Lindsay D. R., and Blache, D.: Natural meth- ods for increasing reproductive efficiency in small ruminants, Anim. Reprod. Sci., 82-83, 231-246, 2004.

McDowell, L. R., Davis, P. A., Cristaldi, L. A., Wilkinson, N. S., Buergelt, C. D., and Van Alstyne, R.: Toxicity of selenium: fear or precaution?, Feedstuffs, 77, 12-13, 2005.

Morán, L., Andres, S., Bodas, R., Benavides, J., Prieto, N., Perez, V., and Giraldez, F. J.: Antioxidants included in the diet of fattening lambs: effects on immune response, stress, welfare and distal gut microbiota, Anim. Feed Sci. Tech., 173, 177-185, 2012.

Morán, L., Giráldez, F. J., Panseri, S., Aldai, N., Jordán, M. J., Chiesa, L. M., and Andrés, S.: Effect of dietary carnosic acid on the fatty acid profile and flavour stability of meat from fattening lambs, Food Chem., 138, 2407-2414, 2013.

Morris, M. C., Schneider, J. A., Li, H., Tangney, C. C., Nag, S., Bennett, D. A., Honer, W. G., and Barnes, L. L.: Brain tocopherols related to Alzheimer's disease neuropathology in humans, Alzheimers Dement., 11, 32-39, 2015.

Navarro-Alarcon, M. and Cabrera-Vique, C.: Selenium in food and the human body: A review, Sci. Total Environ., 400, 115-141, 2008.

Netto, A. S., Zanetti, M. A., Correa, L. B., Del Claro, G. R., Salles, M. S. V., and Vilela, F. G.: Effects of dietary selenium, sulphur and copper levels on selenium concentration in the serum and liver of lamb, Asian Australas. J. Anim. Sci., 27, 1082-1087, 2014.

Niedźwiedzka, K. M., Wąsowska, I., Czauderna, M., Kowalczyk, J., and Pastuszewska, B.: Influence of dietary conjugated linoleic acid isomers and Se on fatty acids profile in blood plasma and some tissues of rats, J. Anim. Feed Sci., 15, 471-489, 2006.

Niedźwiedzka, M. K., Kowalczyk, J., and Czauderna, M.: Influence of selenate and linseed oil on fatty-acid and amino-acid profiles in the liver, muscles, fat tissues and blood plasma of sheep, J. Anim. Feed Sci., 17, 328-343, 2008.

Ogata, J., Yamanishi, H., and Ishibashi-Ueda, H.: Review: Role of cerebral vessels in ischaemic injury of the brain, Neuropath Appl. Neuro., 37, 40-55, 2011.

Orth, M. and Bellosta, S.: Cholesterol: Its regulation and role in central nervous system disorders, Cholesterol, 2012, 292598, doi:10.1155/2012/292598, 2012.

Patterson, E., Wall, R., Fitzgerald, G. F., Ross, R. P., and Stanton, C.: Health implications of high dietary omega-6 polyunsaturated fatty acids, J. Nutr. Metab., 2012, 539426, doi:10.1155/2012/539426, 2012.

Pikul, J., Wójtowski, J., Danków, R., Kuczyńska, B., and Łojek, J.: Fat content and fatty acids profile of colostrum and milk of primitive Konik horses (Equus caballus gmelini Ant.) during six months of lactation, J. Dairy Res., 75, 302-309, 2008.

Rosa, A., Scano, P., Incani, A., Pilla, F., Maestralec, C., Manca, M., Ligios C., and Pani, A.: Lipid profiles in brains from sheep with natural scrapie, Chem. Phys. Lipids., 175-176, 33-40, 2013.

Ruszczyńska, A., Rutkowska, D., Bulska, E., and Czauderna, M.: Effects of carnosic acid, fish oil and seleno-compounds on the level of selenium and fatty acids in lamb muscles, XLV Scientific Session of Group of Animal Nutrition KNZ PAN, Olsztyn, Poland, 21-22 June 2016, Book of Abstracts, in press, 2016.

Schönfeld, P. and Reiser, G.: Why does brain metabolism not favor burning of fatty acids to provide energy? - Reflections on disadvantages of the use of free fatty acids as fuel for brain, J. Cereb. Blood F. Met., 33, 1493-1499, 2013. 
Schweizer, U., Streckfub, F., Pelt, P., Carlson, B. A., Hatfield, D. L., Köhrle, J., and Schomburg, L.: Hepatically derived selenoprotein $\mathrm{P}$ is a key factor to kidney but not for brain selenium supply, Biochem J., 386, 221-226, 2005.

Stadelmann-Ingrand, S., Pontcharraud, R., and Fauconneau, B.: Evidence for the reactivity of fatty aldehydes released from oxidized plasmalogens with phosphatidylethanolamine to form Schiff base adducts in rat brain homogenates, Chem. Phys. Lipids, 131, 93-105, 2004.

Sultana, R., Perluigi, M., and Butterfield, D. A.: Lipid peroxidation triggers neuro-degeneration: A redox proteomics view into the Alzheimer disease brain, Free Radical. Bio. Med., 62, 157-169, 2013.

Suzuki, K., Shimizu T., and Nakata, T.: The cholesterol metabolite cholest-4-en-3-one and its 3-oxo derivatives suppress body weight gain, body fat accumulation and serum lipid concentration in mice, Bioorg. Med. Chem. Lett., 8, 2133-2138, 1998.

Tapiero, H., Townsend, D. M., and Tew, K. D.: The antioxidant role of selenium and selenocompounds, Biomed. Pharmacother., 57, 134-144, 2003.

Tinggi, U.: Essentiality and toxicity of selenium and its status in Australia: A review, Toxicol. Lett., 137, 103-110, 2003.

Uauy, R. and Dangour, A. D.: Nutrition in brain development and aging: role of essential fatty acids, Nutr. Rev., 64, S24-33, 2006.
Vadakkadath Meethal, S. and Atwood, C. S.: The role of hypothalamic-pituitary-gonadal hormones in the normal structure and functioning of the brain, Cell. Mol. Life Sci., 62, 257270, 2005.

Wainwright, P. E.: Dietary essential fatty acids and brain function: a developmental perspective on mechanisms, P. Nutr. Soc., 61, 61-69, 2002.

Weiss, W. P. and Hogan, J. S.: Effect of selenium source on selenium status, neutrophil function, and response to intramammary endotoxin challenge of dairy cows, J. Dairy Sci., 88, 4366-4374, 2005.

Xiao, W. H., Zheng, F. Y., Bennett, G. J., Bordet, T., and Pruss, R. M.: Olesoxime (cholest-4-en-3-one, oxime): Analgesic and neuroprotective effects in a rat model of painful peripheral neuropathy produced by the chemotherapeutic agent, paclitaxel, Pain, 147, 202-209, 2009.

Yu, L. L., Wang, R. L., Zhang, Y. Z., Kleemann, D. O., Zhu, X. P., and Jia, Z. H.: Effects of selenium supplementation on polyunsaturated fatty acid concentrations and anti-oxidant status in plasma and liver of lambs fed linseed oil or sunflower oil diets, Anim. Feed Sci. Tech., 140, 39-51, 2008. 